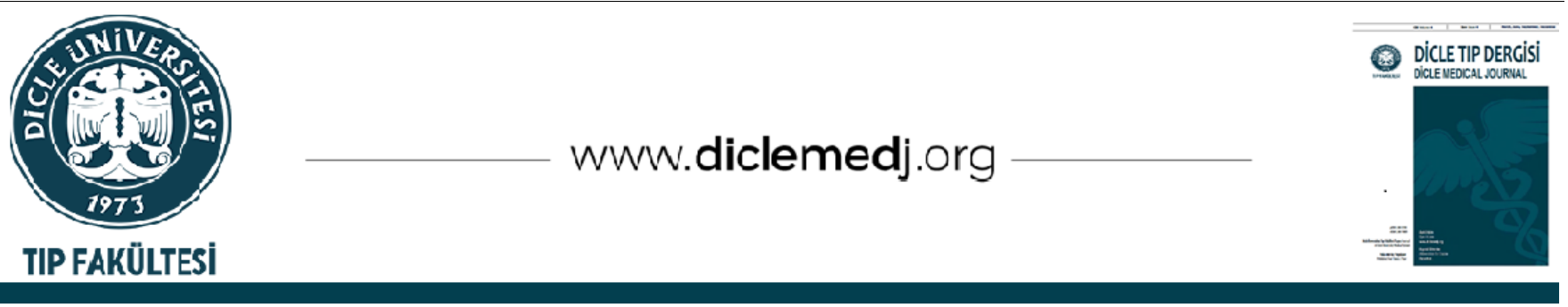

\title{
Postmenopozal Kadınlarda Kemik Mineral Dansitometri Değerleri ile Hematolojik Parametrelerin Karşılaştırılması
}

\author{
Yunus Güzel ${ }^{1}{ }_{1}$, Ali Uyar ${ }^{\left(D_{2}\right.}$, Şadiye Altun Tuzcu ${ }^{2}{ }_{2}$, İhsan Kaplan ${ }^{1}{ }_{1}$, Serhat Ergül ${ }^{\left(D_{3}\right.}$, Mehmet Serdar \\ Yıldırım ${ }^{i}{ }_{4}$, Hikmet Soylu ${ }^{D}$, Bekir Taşdemir ${ }^{D}{ }_{2}$ \\ 1 Sağlık Bilimleri Üniversitesi Gazi Yaşargil Eğitim ve Araștırma Hastanesi, Nükleer Tıp Bölümü Diyarbakır, Türkiye
}

2 Dicle Üniversitesi Tıp Fakültesi, Nükleer Tıp Anabilim Dalı. Diyarbakır, Türkiye

3 Sağlık Bilimleri Üniversitesi Gazi Yaşargil Eğitim ve Araștırma Hastanesi. Fiziksel Tıp ve Rehabilitasyon Kliniği Diyarbakır, Türkiye

4 Sağlık Bilimleri Üniversitesi Gazi Yaşargil Eğitim ve Araştırma Hastanesi, Dahiliye Kliniği Diyarbakır, Türkiye

5 Sağlık Bilimleri Üniversitesi Gazi Yaşargil Eğitim ve Araştırma Hastanesi, Endokrinoloji Kliniği Diyarbakır, Türkiye

Geliș: 01.12.2020; Revizyon: 15.03.2021; Kabul Tarihi: 18.03.2021

Öz

Amaç: Postmenopozal kadınlarda hemogram değerleri, nötrofil lenfosit oranı, trombosit lenfosit oranı ve kemik mineral dansitometri değerleri arasındaki ilișkiyi değerlendirerek hangi parametrenin kemik mineral dansitometri değerleri ile daha güçlü bir ilişki içinde olduğunu belirlemeyi amaçladık.

Yöntemler: Bu çalıșmada vücut kitle indeksi 25-30 arasında değișen, 50-60 yaș arası 64 postmenopozal kadın hastanın kemik mineral dansitometri değerleri, nötrofil lenfosit oranı, trombosit lenfosit oranı ve hemogram parametreleri (beyaz kan hücresi, kırmızı kan hücresi, hemoglobin, platelet, lenfosit, monosit, basofil, nötrofil, eosinofil) geriye dönük olarak incelendi. Kemik mineral yoğunluğunu veya hemogram değerlerini etkileyebilecek klinik durumlar (akut ve kronik enfeksiyonlar, onkolojik, romatolojik ve hematolojik hastalıklar, kronik karaciğer ve böbrek hastalıkları, hiperparatiroidi, hipotiroidi, hipertiroidi, D vitamini eksikliği, steroid kullanımı ve son 1 yıl içerisinde geçirilmiş travma veya kan transfüzyonu öyküsü) çalışma dışı bırakıldı. Daha sonra kemik mineral dansitometri değerleri ile hematolojik parametreler arasında korelasyon analizi yapıldı.

Bulgular: Çalışmamızda platelet lenfosit oranı ile femur boynu kemik mineral dansitesi, femur boynu Z skoru ve femur boynu T skoru arasında istatistiksel olarak anlamlı negatif korelasyon saptandı ( $p=0.004, r=-0.353 ; p=0.005, r=-0.344 ; p=0.004$, $r=-0.359$, respectively). Ayrıca monosit değerleri ile femur boynu kemik mineral dansitesi, femur boynu Z skoru ve femur boynu T skoru arasında istatistiksel olarak anlamlı pozitif korelasyon saptandı ( $\mathrm{p}=0.030, \mathrm{r}=0.272 ; \mathrm{p}=0.038, \mathrm{r}=0.259 ; \mathrm{p}=0.022, \mathrm{r}=0.285$, respectively). Nötrofil lenfosit oranı ile kemik mineral dansitometri parametreleri arasında ilişki saptanmadı.

Sonuç: Yüksek platelet lenfosit oranı ve düșük monosit değeri, menopoz sonrası kemik dansite oranlarındaki değişimleri tahmin etmeye yardımcı olmak için kullanılabilecek basit belirteçler olabilir.

Anahtar kelimeler: DEXA, Kemik Mineral Dansitometri, Platelet Lenfosit Oranı, Monosit

DOI: 10.5798/dicletip.944379

Yazışma Adresi / Correspondence: Yunus Güzel, Gazi Yaşargil Eğitim Ve Araştırma Hastanesi Nükleer Tıp Bölümü, 21070, Kayapınar, Diyarbakır, Türkiye e-mail:drguzel@gmail.com 


\title{
The Comparison of Bone Mineral Densitometry Values and Hematological Parameters in Postmenopausal Women
}

\begin{abstract}
Objective: We aimed to evaluate the relationship between hemogram values, neutrophil lymphocyte ratio, platelet lymphocyte ratio and bone mineral densitometry values in postmenopausal women and thus to determine which parameter is in a stronger relationship with bone mineral densitometry values.

Method: In this study, bone mineral densitometry values, neutrophil lymphocyte ratio, platelet lymphocyte ratio and hematological parameters (white blood cell, red blood cell, hemoglobin, platelet, lymphocyte, monocyte, basophil, neutrophil, eosinophil) of 64 postmenopausal female patients aged 50-60, with a body mass index in the range of 25-30 were retrospectively reviewed. Clinical conditions that may affect bone mineral density or hemogram values (acute and chronic infections, oncological, rheumatological and hematological diseases, chronic liver and kidney diseases, hyperparathyroidism, hypothyroidism, hyperthyroidism, vitamin D deficiency, steroid use, and a history of trauma or blood transfusion in the last one year) were excluded from the study. Then, correlation analysis was performed between bone mineral densitometry values and hematological parameters.
\end{abstract}

Results: In our study, a statistically significant negative correlation was found between platelet lymphocyte ratio and femoral neck bone mineral density, femoral neck Z-score and femoral neck T-score ( $p=0.004, r=-0.353 ; p=0.005, r=-0.344 ; p=0.004, r=-0.359$, respectively). In addition, a statistically significant positive correlation was found between monocyte values and femoral neck bone mineral density, femoral neck Z-score and femoral neck T-score. ( $p=0.030, r=0.272 ; p=0.038, r=0.259 ; p=0.022, r=0.285$, respectively). There was no relationship between neutrophil lymphocyte ratio and bone mineral densitometry parameters.

Conclusion: High platelet lymphocyte ratio and low monocyte value can be simple markers that can be used to help predict changes in bone density ratio after menopause.

Keywords: DEXA, Bone Mineral Densitometry, Platelet Lymphocyte Ratio, Monocyte.

\section{GíRiş}

Osteoporoz (OP), kemik kırılganlığında ve kırılmaya yatkınlıkta artışla sonuçlanan, düşük kemik kütlesi ve kemik dokusunun mikromimarisinin bozulması ile karakterize sistemik bir iskelet hastalığıdır ${ }^{1}$. OP etiyolojisi genetik, beslenme, endokrinolojik, mekanik ve metabolik gibi çeşitli faktörlere ilişkilidir. OP'a bağlı kırıklar yaşlı popülasyonda yaşam kalitesini düşürmekte, sakatlı̆̆a neden olmakta ve bu da ciddi ekonomik kayıplara neden olmaktadır ${ }^{2,3}$. Bu nedenle, OP'un önceden tahmini ve mümkünse önlenmesi büyük önem taşımaktadır.

Yetişkinlik döneminde kemik, eski kemiğin osteoklastlar tarafindan rezorbsiyonu ve yeni kemiğin osteoblastlar tarafından oluşumu yoluyla sürekli olarak yeniden modellenir. Bu iki yakından ilişkili olay, anatomik ve yapısal bütünlüğünü korurken iskeletin yenilenmesinden sorumludur. Postmenopozal ve yaşa bağlı osteopenide kemik oluşumu ve rezorbsiyonu arasındaki uyumsuzluktan aşırı osteoklastogenez ve yetersiz osteoblastogenez sorumludur ${ }^{4}$. Yakın zamanda yapılan bir çalışmada hematopoetik doku hacmiyle kemik mineral dansitesi arasında bir ilişki bildirilmiştir 5 . Ayrıca interlökin 1 (IL-1), interlökin 6
(IL-6) ve tümör nekroz faktörü (TNF- $\alpha$ ) dahil olmak üzere bazı enflamatuar sitokinlerin de deneysel çalışmalarda kemik mineral dansitesi (KMD) ile ilişskili olduğu ve postmenapozal kadınlarda artmış kalça kırığı riskinin artışında önemli bir rol oynadığı öne sürülmüştür6-9.

Tam kan sayımı çeşitli enflamatuar hastalıklarla ilişkili olup basit, kolayca bulunabilen ve ucuz bir testtir. Nötrofiller, lenfositler ve trombositler enflamasyona bağlı değişikliklerde rol oynarken bir yandan da enflamasyonu düzenlerler. Son zamanlarda, kardiyovasküler hastalıklar, çeşitli maligniteler, romatolojik hastalıklar, KOAH, pankreatit ve enflamatuar barsak hastalıklarında nötrofil lenfosit oranı (NLO) ve platelet lenfosit oranı (PLO) sistemik enflamasyon belirteçleri olarak öne sürüldügü çok sayıda çalışma yapılmıştır. $\mathrm{Bu}$ belirteçler, enflamasyona dayalı yararlı prognostik göstergeler olup bazı çalışmalarda kardiyovasküler hastalıklar ve malignitelerde olumsuz sonuçların öngörülmesinde NLO ve PLO'ın tek başına beyaz kan hücrelerine göre üstün olduğu gösterilmiștir ${ }^{10-15}$. Ayrıca, son zamanlarda bazı araştırmacılar bazı hemogram parametrelerinin, NLO ve PLO'un azalmış KMD ve OP ile ilişkisini değerlendirmiş 
ancak çalışma sonuçları arasında bir takım çelişkiler bulunmuş ve bu konuda henüz bir konsensus oluşmamıştır ${ }^{16-22}$. Bu durumun netlik kazanması için daha fazla çalışmaya ihtiyaç bulunmaktadır. Bu çalışmanın amacı, postmenopozal kadınlarda KMD ile hemogram parametrelerinin, NLO ve PLO'nı karşılaştırmaktır.

\section{YÖNTEMLER}

Çalışmaya Dicle Üniversitesi Tıp Fakültesi Nükleer Tıp Anabilim Dalı'nda endikasyon gereği Temmuz 2019 ile Temmuz 2020 tarihleri arasında KMD ölçümü yapılmış ve verilerine eksiksiz bir şekilde ulaşılan, 50-60 yaş arası, vücut kitle indeksi 25-30 aralığında olan, KMD ölçümü ile arasında maksimum bir ay olmak şartı ile hemogram sonucu olan postmenopozal kadın hastalar retrospektif olarak tarandı. KMD veya hemogram verilerini tek taraflı etkileyebilecek klinik durumlardan; akut ve kronik enfeksiyonlar, onkolojik, romatolojik ve hematolojik hastalıklar, kronik karaciğer ve kronik böbrek hastalıkları, hiperparatiroidi, hipotiroidi, hipertiroidi, D vitamini eksikliği, steroid kullanımı ve son 1 yıl içerisinde travma ve kan transfüzyonu tespit edilen hastalar çalışma dışı bırakıldı.

Vücut kitle indeksi (VKI), kilogram cinsinden ağırlığın metre kare cinsinden hasta boyuna bölünmesiyle hesaplandı.

DEXA ölçümü: KMD, çift enerjili X-ışını absorpsiyometrisi (DXA, Discovery QDR4500 A/SL, Hologic, Bedford, MA, USA) kullanılarak lomber bölge ve femoral bölgeler yavaş modda ve sırtüstü pozisyonda elde edilen görüntülerden hesaplandı.

$\mathrm{Bu}$ çalışma yerel iyi klinik uygulamalar (GCP) kılavuzuna ve mevcut yasalara uygun olarak gerçekleştirilmiş olup hasta verilerinin kullanımı için Dicle Üniversitesi Tıp Fakültesi Etik Kurulundan onay alınmıștır (izin no:352/16.07.2020).

\section{İstatistik}

İstatistiksel analiz SPSS (Statistical Package for Social Sciences, IBM Corporation, Armonk, New York, USA) yazılımı versiyon 21 kullanılarak yapıldı. Tanımlar ortalama ve standart sapma olarak tanımlandı. Kategorik değişkenler vaka sayısı ve yüzde değeri olarak sunuldu. Sürekli değişkenlerin normal dağılıp dağılmadığını belirlemek için Kolmogorov-Smirnov ve Shapiro-Wilk testleri kullanıldı. Normal dağılıma uygun değişkenler arasında korelasyon olup olmadığını belirlemek için Pearson korelasyon testleri, normal dağılım göstermeyen değişkenler arasında korelasyon olup olmadığını belirlemek için Spearman korelasyon testleri kullanıldı. 0.05'in altındaki p değerlerinin istatistiksel olarak anlamlı olduğu kabul edildi.

\section{BULGULAR}

Çalışmaya katılan 64 hastanın yaş ortalamaları $54.8 \pm 2,9$ yll ve vücut kitle indeksleri $27,7 \pm 1,25 \mathrm{~kg} /$ m2 olarak ölçüldü. Hastaların hemogram ve DEXA değerleri Tablo 1 de ayrı ayrı verildi.

Tablo I: Nötrofil lenfosit oranı, platelet lenfosit oranı, hemogram parametreleri ve kemik mineral dansitesi ortalama değerleri ve standart deviasyonları.

\begin{tabular}{|lc|}
\hline Parametreler ve Oranlar & $\begin{array}{c}\text { Ortalama } \pm \text { Standard } \\
\text { Deviasyon }\end{array}$ \\
\hline Yaş & $54,8 \pm 2,9$ \\
VKi & $27,7 \pm 1,25$ \\
Wbc & $6,79 \pm 1,39$ \\
Rbc & $4,66 \pm 0,283$ \\
Plt & $13,6 \pm 0,903$ \\
Lym & $248 \pm 55,1$ \\
Mon & $2,39 \pm 0,544$ \\
Baz & $0,486 \pm 0,141$ \\
Neu & $0,0805 \pm 0,0743$ \\
Eos & $3,68 \pm 0,997$ \\
Lomber vertebra KMD & $0,163 \pm 0,104$ \\
Lomber vertebra T SKOR & $0,840 \pm 0,123$ \\
Lomber vertebra Z SKOR & $-1,88 \pm 1,12$ \\
Femur boynu KMD & $-0,794 \pm 1,12$ \\
Femur boynu T SKOR & $0,741 \pm 0,099$ \\
Femur boynuZ SKOR & $-0,972 \pm 0,887$ \\
Femur total KMD & $0,0750 \pm 0,904$ \\
Femur total T SKOR & $0,928 \pm 0,113$ \\
Femur total Z SKOR & $-0,116 \pm 0,925$ \\
NLO & $0,583 \pm 0,932$ \\
PLO & $1,59 \pm 0,473$ \\
\hline VKI:VuCut & $107 \pm 28,6$ \\
\hline
\end{tabular}

VKi: Vucut kitle indeksi, Wbc: Beyaz kan hücresi, Rbc: Kırmızı kan hücresi, Hgb: Hemoglobin, Plt: Platelet, Lym: Lenfosit, Mon: Monosit, Bas: Basofil, Neu: Nötrofil, Eos: Eosinofil, NLO: Nötrofil lenfosit oranı, PLO: Platelet lenfosit oranı, KMD: Kemik mineral dansitesi 
Çalışmamızda PLO ile femur boynu KMD, femur boynu Z skoru ve femur boynu T skoru arasinda istatistiksel olarak anlamlı negatif korelasyon saptand $(\mathrm{p}=0.004, \mathrm{r}=-0.353$; $\mathrm{p}=0.005, \mathrm{r}=-0.344$; $\mathrm{p}=0.004, \mathrm{r}=-0.359$, sirasiyla). Ayrica monosit değerleri ile femur boynu KMD, femur boynu Z skoru ve femur boynu $\mathrm{T}$ skoru arasinda

Tablo II: Hemogram parametreleri ile kemik mineral dansitesi değerleri arasındaki korelasyon analizi sonuçları

\begin{tabular}{|c|c|c|c|c|c|c|c|c|c|c|c|c|}
\hline & & WBC & RBC & Hgb & Plt & Lym & Mon & Bas & Neu & Eos & NLO & PLO \\
\hline & & $r$ & $r$ & $r$ & $r$ & $r$ & $r$ & $r$ & $r$ & $r$ & $r$ & $r$ \\
\hline & & $P$ & $P$ & $P$ & $p$ & $p$ & $p$ & $p$ & $p$ & $p$ & $p$ & $p$ \\
\hline \multirow[t]{2}{*}{$\begin{array}{l}\text { Lumbal } \\
\text { Skor }\end{array}$} & $\mathrm{T}$ & 0,043 & 0,067 & $-0,028$ & $-0,079$ & 0,110 & 0,066 & 0,095 & $-0,010$ & $-0,124$ & $-0,057$ & $-0,116$ \\
\hline & & 0,734 & 0,599 & 0,824 & 0,535 & 0,389 & 0,604 & 0,454 & 0,939 & 0,328 & 0,655 & 0,361 \\
\hline \multirow[t]{2}{*}{$\begin{array}{l}\text { Lumbal } \\
\text { Skor }\end{array}$} & Z & 0,059 & 0,045 & $-0,087$ & $-0,072$ & 0,115 & 0,101 & 0,103 & 0,014 & $-0,154$ & $-0,046$ & $-0,193$ \\
\hline & & 0,644 & 0,723 & 0,495 & 0,572 & 0,366 & 0,427 & 0,416 & 0,912 & 0,225 & 0,719 & 0,126 \\
\hline \multirow[t]{2}{*}{$\begin{array}{l}\text { Lumbal } \\
\text { KMD }\end{array}$} & $\mathrm{T}$ & 0,047 & 0,060 & $-0,033$ & $-0,087$ & 0,111 & 0,068 & 0,094 & $-0,009$ & $-0,123$ & $-0,059$ & $-0,189$ \\
\hline & & 0,714 & 0,635 & 0,796 & 0,495 & 0,383 & 0,594 & 0,462 & 0,947 & 0,333 & 0,646 & 0,135 \\
\hline \multirow[t]{2}{*}{$\begin{array}{l}\text { F. Boynu T } \\
\text { Skor }\end{array}$} & $\mathrm{T}$ & 0,174 & $-0,057$ & 0,009 & $-0,243$ & 0,194 & 0,259 & 0,074 & 0,089 & 0,060 & $-0,047$ & $-0,344$ \\
\hline & & 0,169 & 0,653 & 0,941 & 0,053 & 0,126 & 0,038 & 0,562 & 0,482 & 0,636 & 0,713 & 0,005 \\
\hline \multirow{2}{*}{\multicolumn{2}{|c|}{$\begin{array}{l}\text { F. Boynu Z } \\
\text { Skor }\end{array}$}} & 0,210 & $-0,045$ & $-0,025$ & $-0,231$ & 0,209 & 0,285 & 0,095 & 0,144 & 0,036 & $-0,010$ & $-0,359$ \\
\hline & & 0,095 & 0,725 & 0,843 & 0,067 & 0,098 & 0,022 & 0,454 & 0,258 & 0,779 & 0,936 & 0,004 \\
\hline \multirow{2}{*}{\multicolumn{2}{|c|}{$\begin{array}{l}\text { F. Boynu } \\
\text { KMD }\end{array}$}} & 0,185 & $-0,056$ & 0,013 & $-0,252$ & 0,196 & 0,272 & 0,076 & 0,103 & 0,050 & $-0,036$ & $-0,353$ \\
\hline & & 0,143 & 0,658 & 0,920 & 0,045 & 0,121 & 0,030 & 0,548 & 0,419 & 0,694 & 0,776 & 0,004 \\
\hline \multirow[t]{2}{*}{$\begin{array}{l}\text { F. Total T } \\
\text { Skor }\end{array}$} & $\mathrm{T}$ & 0,100 & $-0,059$ & $-0,028$ & $-0,072$ & 0,178 & 0,238 & 0,214 & 0,006 & 0,021 & $-0,148$ & $-0,203$ \\
\hline & & 0,430 & 0,644 & 0,826 & 0,573 & 0,158 & 0,059 & 0,089 & 0,960 & 0,868 & 0,243 & 0,107 \\
\hline \multirow[t]{2}{*}{$\begin{array}{l}\text { F. Total } \\
\text { Skor }\end{array}$} & Z & 0,108 & $-0,057$ & $-0,045$ & $-0,059$ & 0,179 & 0,253 & 0,192 & 0,015 & 0,006 & $-0,143$ & $-0,195$ \\
\hline & & 0,397 & 0,656 & 0,723 & 0,645 & 0,157 & 0,043 & 0,129 & 0,905 & 0,961 & 0,259 & 0,123 \\
\hline \multirow[t]{2}{*}{$\begin{array}{ll}\text { F. } & \text { Tota } \\
\text { KMD } & \end{array}$} & & 0,098 & $-0,057$ & $-0,020$ & $-0,080$ & 0,172 & 0,234 & 0,220 & 0,007 & 0,021 & -141 & -209 \\
\hline & & 0,442 & 0,657 & 0,875 & 0,532 & 0,175 & 0,063 & 0,081 & 0,956 & 0,867 & 0,267 & 0,107 \\
\hline
\end{tabular}

Wbc: Beyaz kan hücresi, Rbc: Kırmızı kan hücresi, Hgb: Hemoglobin, Plt: Platelet, Lym: Lenfosit, Mon: Monosit, Bas: Basofil, Neu: Nötrofil, Eos: Eosinofil, NLO: Nötrofil lenfosit oranı, PLO: Platelet lenfosit oranı, KMD: Kemik mineral dansitesi, F.: Femur

TARTIŞMA

Hemogram parametreleri ile KMD karşılaştırıldığı bu retrospektif çalışmadaki en istatistiksel olarak anlaml pozitif korelasyon saptandı ( $\mathrm{p}=0.030, \mathrm{r}=0.272 ; \mathrm{p}=0.038, \mathrm{r}=0.259$; $\mathrm{p}=0.022, \quad \mathrm{r}=0.285$, sirasiyla). Diğer tüm hemogram ve DEXA verileri ile NLO ve DEXA verileri arasında istatistiksel olarak anlamlı bir korelasyon saptanmadı (Tablo 2). 
Literatürde NLO ve PLO gibi enflamatuar parametreler ile KMD arasında çelişkili veriler bulunmaktadır. Öztürk ve arkadaşlarının yaptığı osteopeni veya OP'u olan veya olmayan 1635 hasta üzerinde yapılan bir çalışmada, NLO değerinin OP'lu hasta grubunda osteopeni ve kontrol grubuna göre belirgin arttığını gösterdi16. Benzer şekilde diyabeti olmayan postmenopozal 233 hasta üzerinde yapılan bir başka çalışmada NLO düzeyinin postmenopozal OP grubunda daha yüksek olduğu izlenmiştir ${ }^{17}$. Liu ve arkadaşları $C$ reaktif protein (CRP) ve NLO'un postmenopozal kadınlarda osteopeni için belirteç olabileceğini göstermiş ve benzer şekilde Yılmaz ve arkadaşlarının 438 hastada yapmış olduğu çalışmada NLO'un CRP'den daha iyi bir belirteç olabileceğini bulmuştur ${ }^{18-19}$. Son zamanlarda yapılan başka bir çalışmada NLO ile KMD arasında önceki çalışmalar ile benzer şekilde negatif ilişki bulunmuş olup PLO ile herhangi bir ilişki bulunmamıștır ${ }^{20}$. Ancak Köseoğlu'nun yapmış olduğu çalışmada enflamatuar bir belirteç olan PLO'un değeri, düşük KMD grubunda önemli ölçüde daha yüksek bulunmuştur ${ }^{21}$. Benzer şekilde Eroğlu ve arkadaşları tarafından son zamanlarda 252 hasta üzerinde yapılan bir başka çalışmada PLO değerinin osteopeni ve OP grubunda belirgin derecede arttığı ve PLO'un menopoz sonrası OP'u tahmin etmede basit ve uygun maliyetli bir test olduğunu söylemişlerdir ${ }^{22}$. Bizim çalışmamızda da son iki çalışma ile benzer şekilde PLO ve KMD arasında negatif korelasyon saptanmış olup NLO ile anlamlı olabilecek her hangi bir ilişki saptanmamıştır.

Literatürde hemogram parametreleri ile KMD arasındaki çalışmalar sınırlı sayıdadır. Lei ve arkadaşlarının yapmış olduğu hayvan deneyleri, yumurtalıkları alınmış sıçanların KMD'sinin 4. haftada Sham grubuna kiyasla başlangıçta önemli ölçüde azalmadığını, ancak yağ dokusu hacminin önemli ölçüde arttığını göstermiştir. Sham grubuna kiyasla yumurtalıkları alınmış grubunun 8. haftadan sonra, KMD‘sinin önemli ölçüde azaldığı, hematopoetik doku hacminin azaldığı buna karşın adipoz doku hacminin arttığı izlenmiş olup megakaryosit sayılarınını azaldığı ancak osteoklast ve mast hücre sayısı arttığı dikkati çekmiştir. Yumurtalıkları alınmış gruptaki sıçanlarda 12. haftaya gelindiğinde trabeküler kemik hacmi ve osteoblast sayısı önemli ölçüde azaldığı izlenmiştir. Böylece araştırmacılar, yumurtalıkları alınmış grupta KMD'sinin azaldığında, kemik iliği hematopoetik fonksiyonunun da azaldığını düşünülebilir sonucuna varmışlardır ${ }^{5}$. Buna karşın Kim ve arkadaşlarının postmenapozal kadınlarda periferal kan hücreleri ile kemik mineral yoğunluğu arasındaki ilişkiyi araştırdıkları beyaz kan hücresi, kırmızı kan hücresi ve trombosit sayıları ile KMD arasında pozitif bir ilişki olduğunu gösterdiler. Ayrıca multipl lineer regresyon analizi sonucu osteoporoz için yaş, ağırlık, alkalen fosfataz ve kırmızı kan hücresi değerlerini bağımsız prognostik faktörler olarak buldular ${ }^{23}$. Korkmaz ve arkadaşlarının 371 hasta üzerinde yapmış olduğu çalışmada anemik kadınlarda femur ve omurga T skor, $\mathrm{Z}$ skor ve BMD değerlerinin istatistiki anlamlı olacak şekilde daha düşük olduğunu bulmuşlardır ${ }^{24}$. Ayrıca son zamanlarda Li ve arkadaşlarının 673 hasta üzerinde yapmış olduğu bir başka çalışmada postmenopozal kadınlarda araştırdıkları beyaz kan hücresi, kırmızı kan hücresi ve hemoglobin değerleri osteoporozlu olanlarda nonosteoporotik olanlara göre daha yüksek bulunmuş olup lumbal vertebra KMD değeri kırmızı kan hücresi, hemoglobin ve platelet sayıları ile negatif korele iken, femur KMD değeri beyaz kan hücresi, kırmızı kan hücresi, hemoglobin ve platelet sayıları ile negatif korele bulundu. Aynı çalışmada multivariant regresyon analizi ile lumbar KMD yaş boy, kilo, BMI, hemoglobin ile ilişkili iken femur KMD, yaş, BMI ve kırmızı kan hücresi ile ilişkili bulundu ${ }^{25}$. Ancak bizim çalışmamızda beyaz kan hücresi, kırmızı kan 
hücresi, hemogram ve trombosit sayımları ile KMD arasında herhangi bir ilişki saptanmadı. Bununla birlikte çalışmamızda yukarıda belirtilen diğer çalışmalardan farklı olarak monosit sayısı ile femur KMD arasında istatistiksel olarak anlamlı pozitif bir ilișki saptanmış olup bu bulgu literatürde ilk kez saptandl.

Çalışmamızın retrospektif olması, kontrol grubunun bulunmaması ve hasta sayısının az olması zayıf yönleri olarak sayılabilir. Her ne kadar çalışmamız diğer çalışmalara kurgu olarak benzer özellikler taşısa da bizim çalışmamızdaki örneklemin belirli bir yaş ve VKİ aralığında olması ve yine örneklemin KMD değerlerini etkileyebilecek diğer hastalıkların neredeyse tamamından arındırılmış olması çalışmamızın güçlü ve ayırt edici yönleridir.

\section{SONUÇ}

Yüksek PLO ve düşük monosit değeri, menopoz sonrası OP'u tahmin etmeye yardımcı olmak için kullanılabilecek basit belirteçler olabilir. Çalışmamızda literatürde bir ilk olarak düşük monosit değeri ile düşük KMD değerleri arasında pozitif korelasyon saptanmıştır. Bununla birlikte, bu alanda daha geniş hasta gruplarını içeren daha fazla çalışmaya ihtiyaç vardır.

Etik Kurul Kararı: Bu çalıșma yerel iyi klinik uygulamalar (GCP) kılavuzuna ve mevcut yasalara uygun olarak gerçekleştirilmiş olup hasta verilerinin kullanımı için Dicle Üniversitesi Tıp Fakültesi Etik Kurulundan onay alınmıştır (izin no:352/16.07.2020).

Çıkar Çatışması Beyanı: Yazarlar çıkar çatışması olmadığını bildirmişlerdir.

Finansal Destek: Bu çalışma her hangi bir fon tarafından desteklenmemiştir.

Declaration of Conflicting Interests: The authors declare that they have no conflict of interest.
Financial Disclosure: No financial support was received.

\section{KAYNAKLAR}

1. Consensus development conference: diagnosis, prophylaxis, and treatment of osteoporosis. Am J Med. 1993; 94: 646-50.

2. Harvey N, Dennison E, Cooper C. Osteoporosis: impact on health and economics. Nat Rev Rheumatol. 2010; 6: 99-105.

3. Yun AJ, Lee PY. Maldaptation of the link between inflammation and bone turnover may be a key determinant of osteoporosis. Med Hypotheses. 2004; 63: 532-7.

4. Manolagas SC, Jilka RL. Bone marrow, cytokines, and bone remodeling. Emerging insights into the pathophysiology of osteoporosis. N Engl J Med. 1995; 332: 305-11.

5. Lei Z, Xiaoying Z, Xingguo L. Ovariectomyassociated changes in bone mineral density and bone marrow haematopoiesis in rats. Int J Exp Pathol. 2009; 90: 512-9.

6. Kimble RB, Matayoshi AB, Vannice JL, et al. Simultaneous block of interleukin-1 and tumor necrosis factor is required to completely prevent bone loss in the early postovariectomy period. Endocrinology. 1995; 136: 3054-61.

7. Nanes MS. Tumor necrosis factor-alpha: molecular and cellular mechanisms in skeletal pathology. Gene. 2003; 321: 1-15.

8. Kutlucan A, Tunc S, Baltacı D, ve ark. Behçet hastalarında serum TNF- \&alpha; ve osteoprotegerin düzeyi ve kemik kitle yoğunluğu. Dicle Tıp Dergisi. 2012; 39: 325-30.

9. Barbour KE, Boudreau R, Danielson ME, et al. Inflammatory markers and the risk of hip fracture: the Women's Health Initiative. J Bone Miner Res. 2012; 27: 1167-76.

10. Papa A, Emdin M, Passino C, et al. Predictive value of elevated neutrophil-lymphocyte ratio on cardiac mortality in patients with stable coronary artery disease. Clin Chim Acta. 2008; 395: 27-31. 
11. Can C. Correlation of (18F) FDG PET/CT Parameters with Haematological Parameters in Esophageal Cancers and the Effect of These Parameters on Survival. Dicle Tıp Dergisi, 2020; 47: 556-67.

12. Torun S, Tunc BD, Suvak B, et al. Assessment of neutrophil-lymphocyte ratio in ulcerative colitis: a promising marker in predicting disease severity. Clin Res Hepatol Gastroenterol. 2012; 36: 491-7.

13. Zengin 0 , Onder ME, Kalem A, et al. New inflammatory markers in early rheumatoid arthritis. Z Rheumatol. 2018; 77: 144-50.

14. Sun X, Liu X, Liu J, et al. Preoperative neutrophilto-lymphocyte ratio plus platelet-to-lymphocyte ratio in predicting survival for patients with stage III gastric cancer. Chin J Cancer. 2016; 35: 57.

15. Tanrikulu AC, Abakay A, Komek H, Abakay O. Prognostic value of the lymphocyte-to-monocyte ratio and other inflammatory markers in malignant pleural mesothelioma. Environ Health Prev Med. 2016; 21: 304-11.

16. Öztürk ZA, Yesil Y, Kuyumcu ME, et al. Inverse relationship between neutrophil lymphocyte ratio (NLR) and bone mineral density (BMD) in elderly people. Arch Gerontol Geriatr. 2013; 57: 81-5.

17. Huang C, Li S. Association of blood neutrophil lymphocyte ratio in the patients with postmenopausal osteoporosis. Pak J Med Sci. 2016; 32: 762-5.

18. Liu W, Huang Z, Tang S, Wei S, Zhang Z. An evaluation of homocysteine, C-reactive protein, lipid levels, neutrophils to lymphocyte ratio in postmenopausal osteopenic women. Gynecol Endocrinol. 2016; 32: 446-8.

19. Yilmaz H, Uyfun M, Yilmaz TS, et al. Neutrophillymphocyte ratio may be superior to C-reactive protein for predicting the occurrence of postmenopausal osteoporosis. Endocr Regul. 2014; 48: 25-33.

20. Lee SH, Ryu SY, Park J, et al. The Relationship of Neutrophil-Lymphocyte Ratio and PlateletLymphocyte Ratio with Bone Mineral Density in Korean Postmenopausal Women. Chonnam Med J. 2019; 55: 150-5.

21. Koseoglu SB. Bone loss \& platelet-to-lymphocyte ratio. Biomark Med. 2017; 11: 5-10.

22. Eroglu S, Karatas G. Platelet/lymphocyte ratio is an independent predictor for osteoporosis. Saudi Med J. 2019; 40: 360-6.

23. Kim HL, Cho HY, Park IY, et al. The positive association between peripheral blood cell counts and bone mineral density in postmenopausal women. Yonsei Med J. 2011; 52: 739-45.

24. Korkmaz U, Korkmaz N, Yazici S, et al. Anemia as a risk factor for low bone mineral density in postmenopausal Turkish women. Eur J Intern Med. 2012; 23: 154-8.

25. Li L, Ge JR, Chen J, et al. Association of bone mineral density with peripheral blood cell counts and hemoglobin in Chinese postmenopausal women: A retrospective study. Medicine (Baltimore). 2020; 99: e20906. 